\title{
Silicone breast implants: the situation in 1991
}

Doubt as to the safety of silicone-filled breast implants is not new, but 1991 was a year in which a series of events threw the issue into sharp focus. Not surprisingly, those events centred primarily on North America, for it seems very likely that the bulk of silicone implants have been used in Canada and the United States, and it is also there that a number of crusades against these products have been undertaken.

The implantation of such devices either for purely cosmetic reasons or to restore the form of the breast after partial mastectomy has been increasingly popular for at least fifteen years; in 1976, when the F.D.A. was endowed with the authority to regulate these and other medical appliances, they were already in use, and by 1991 the agency estimated that some two million American women had received implants either for breast augmentation or reconstruction.

In the course of the years there have been sporadic reports of complications following the use of these implants and a certain amount of litigation against their manufacturers or the cosmetic surgeons who had implanted them. Some of these seem to have resulted from dissatisfaction with the results of the method as such; others were clearly attributable to unskilful implantation, failure on the part of the surgeon or the manufacturer to provide adequate warnings, or to defects of particular brands, since several variants have been marketed. In April 1991, the Même mammary implant, produced in Wisconsin, was removed from the market in Canada and the U.S.A., and agencies in both countries warned against its further use. The Même implant, a silicone-filled sac surrounded by a polyurethane coating, had by that time been implanted in some 200,000 women in the United States and 17,000 women in Canada. This appears to have been a case of particular risks associated with the brand; the Même implant used a polyurethane foam coating, and a study sponsored by the F.D.A. showed that this could release significant amounts of the carcinogen 2,4-toluene diamine as a degradation product.

The Même implant was involved in an unsuccessful 1989 case brought by a British Columbia woman against a general surgeon and a cosmetic surgeon, who in her view had failed to warn her of the complications which might arise if a subcutaneous mastectomy were to be required after insertion of a Même implant. In 1991 this was followed by the filing by a Quebec woman of a request for a class-action suit against the product's manufacturer, its parent company and Canadian distributor on behalf of all the 14,000 Quebec women who had received the Même implant. The fact that actions such as these have been brought says rather less than the later decision by the corporation itself to withdraw the product, which by all accounts indeed reflects the product's poor track record. 
Before the 1991 request for a Canadian class action could be dealt with judicially, there was an important development in the U.S.A. where both the independent Health Research Group and the Congressman Ted Weiss called for action; the former contended that all silicone filled breast implants were unsafe, and that the polyurethane-covered types were "particularly noxious", while Weiss accused the F.D.A. of inaction in the face of accumulating evidence of risk.

A crucial further development occurred in November 1991 when the General and Plastic Surgery Devices Panel, a group of outside experts, advised the F.D.A. that data submitted by four manufacturers of silicone gel-filled breast implants did not provide reasonable assurance of the safety and effectiveness of these devices. Dr. Elizabeth Connell of Emory University School of Medicine, who chaired the panel, emphasized in public that the group had not found evidence that the implants were unsafe, but rather that there was not enough information about the risk and benefits of their use. In the face of incomplete evidence, however, the panel voted unanimously to advise the agency that silicone breast implants served a public health need, and that they should continue to be available while the manufacturers collected the additional data; the panel urged the F.D.A. to hold the manufacturers accountable for collecting such evidence without delay.

At the time of writing, a decision by the F.D.A. on the future of the four brands of implant currently on sale was still awaited; it was due very early in 1992, and there seemed little doubt that the F.D.A. would allow the continued sale of the devices pending further evidence from the manufacturers. That would be in accordance with the panel's advice, and it would also parallel the approach taken by the agency in the cases of other devices (such as intra-uterine contraceptives) and many older drugs, wherever the efficacy and safety issue is not entirely settled at the time when the F.D.A. is given the authority to deal with them.

Several matters remain, however, unclear. One is how the term "efficacy" is to be interpreted in this case, and then weighed against risk. There is no doubt that silicone implants are regarded as desirable by many women, just as they are rejected by others; the issue can be purely cosmetic, but there are instances in which restoration, maintenance or improvement of the breast profile is a matter of psychological and medical importance, particularly in some post-mastectomy subjects. Whether the implantation of silicone will give a satisfactory cosmetic result is as dependent on the skill of the cosmetic surgeon as on the nature and form of the device. How long it will remain satisfactory seems very unclear; it is not unlikely that many subjects will find the implant disfiguring as breast tissue atrophies later in life, and will call for its removal, but these are long-term issues on which no rapid information can be expected. The shorter-term problem seems to be one of cosmetic failure, with the need for implant replacement in a third or more of cases within a very few years. Overall, one faces the uncertainty resulting from the fact that benefit is in many cases primarily a matter of patient demand and subjective satisfaction. Cosmetic surgeons have been quoted as declaring that very few women withdraw even after an open explanation of the possible risks, and that the demand for the Même implant has persisted despite its well-publicized withdrawal.

The risk issue is more clear-cut, at least qualitatively, and is illuminated by very 
large numbers of published case reports. A device can, despite skilful implantation, prove harmful if there is any leakage of silicone into the surrounding tissue (producing a local tissue reaction and creating the risk of silicone embolus or loss of silicone into the lymphatic system) or if the material used to provide the outer coating is either irritant, capable of rupture or partial dissolution (e.g. leaching of emulsifiers into the tissue) or likely to change its consistency over a long period of time (becoming either brittle or porous). There seems to be a real but extraordinarily small risk of carcinogenesis. Beyond that, the consequences of damage to the sac in the event of breast injury need to be considered, as does the reaction which can occur if pregnancy stimulates development of the surrounding mammary tissue. Finally the presence of an implant could impede reliable mammography to detect tumours. This list - rather more elaborate than that provided by the advisory panel - reflects the sort of issues on which the F.D.A. is likely to want hard data. Since adequate animal models hardly exist one suspects that the only solution will lie in the intensification of long-term post-marketing surveillance in human subjects, and the progressive improvement or replacement of any device which proves to be problematical.

Litigation, in the meantime, is unlikely to fade out. In December, precisely a month after the panel's report to the F.D.A., a federal court jury in San Francisco ordered the Dow Corning Corporation to pay no less than $\$ 7.3$ million in compensatory and punitive damages to one Marian Hopkins in whom mixed connective tissue disease was diagnosed some two years after the insertion of two implants; it was discovered that the implants had ruptured and the silicone gel had spread into her lymph system. The award will be appealed, the company arguing that it reflects primarily the influence of a "sensational media environment" surrounding these products.

At the time of writing, the future acceptability of silicone breast implants is still highly uncertain. A 45-day FDA moratorium on their use expired in February, and a committee which met to advise on future policy could only conclude that the extent of risk remained unsettled and required further study.

February 1992

M.N.G. Dukes MD MA LLM

Professor of Drug Policy Studies, University of Groningen, The Netherlands

\section{References}

Wolf N. The Beauty Myth, Random House, Toronto, 1991.

Spurgeon D. The Même implant creates a scientific storm. Can Med Assoc J 1991;145:54-60.

F.D.A. Talk Paper. Panel issues breast implant recommendations. Food and Drug Administration, 15 November, 1991.

Faludi R.F. Dow Corning ordered to pay in implant case. Wall Street J., 16 December, A6, 1991. 